\title{
Çokgenlerle İlgili Kavram Yanılgıları ve Olası Nedenler ${ }^{1}$
}

\author{
Yasin $\mathrm{AY}^{2}$ \\ Alper BAŞBAY ${ }^{3}$
}

Geliş Tarihi: 2016-10-13

Kabul Tarihi: 2017-01-20

\section{Öz}

Araştırmada 7. sınıf öğrencilerinin çokgenler konusuyla ilgili kavram yanılgılarını ve bu yanılgıların nedenlerini belirlemek amaçlanmıştır. Ardışık açıklayıcı desenin kullanıldığı araştırma, 2013-2014 eğitim öğretim yılında yürütülmüştür. Araştırmanın örneklemini İzmir ili merkez ilçelerinden sistematik örnekleme yöntemiyle belirlenen okullarda öğrenim gören 424 öğrenci oluşturmaktadır. Araştırma verilerinin toplanmasında iki aşamalı Çokgenler Kavram Yanılgılarını Belirleme Testi (ÇKYBT) ile Görüşme Formu kullanılmıştır. ÇKYBT’de 15 madde yer almakta olup, testin KR-20 güvenirlik katsayıs1 .74 olarak elde edilmiştir. Öğrencilerin verdiği yanıtlar ve yaptıkları açıklamalar sınıflandırılarak ne tür kavram yanılgıları olduğu tespit edilmiştir. Görüşme formu ise kavram yanılgılarının olası nedenlerini belirlemek amacıyla kullanılmıştır. ÇKYBT'den elde edilen verilerin analizinde yüzde ve frekans hesaplamaları kullanılırken, görüşmelerden elde edilen veriler içerik analizine tabi tutulmuştur. Bulgulara göre öğrencilerin çokgenlerle ilgili kavramların özellikleri, bu kavramların sınıflandırılması ve tanımlanması, aralarındaki ilişkilerin belirlenmesi ile ilgili kavram yanılgıları olduğu belirlenmiştir. Bu yanılgıların temelinde öğrencilerin kendisinden, öğretmenden, kullanılan materyal, araç gereçler ve dilin çeşitli özellikleri gibi etmenlerin olduğu tespit edilmiştir.

Anahtar Kelimeler: Matematik, geometri, çokgenler, kavramlar, kavram yanılgıları, kavram yanılgılarının nedenleri

\footnotetext{
${ }^{1} \mathrm{Bu}$ makale, birinci yazarın Ege Üniversitesi Sosyal Bilimler Enstitüsü tarafından 2014 yılında kabul edilen ve Doç. Dr. Alper BAŞBAY danışmanlığında yürütülen yüksek lisans tezinin bir bölümünden üretilmiştir.

${ }^{2}$ Araş. Gör.,Ege Üniversitesi Eğitim Fakültesi, Eğitim Bilimleri Bölümü, yasin.ay@ege.edu.tr

${ }^{3}$ Doç. Dr. Ege Üniversitesi Eğitim Fakültesi, Eğitim Bilimleri Bölümü, alper.basbay@ege.edu.tr
} 


\title{
Misconceptions about Polygons and Their Possible Reasons
}

\begin{abstract}
It is aimed to determine misconceptions of seventh graders about polygons and the reasons for these misconceptions. The study was carried out using sequential explanatory design and conducted in the 2013-2014 academic year. The sample of the study consisted of 424 students determined by systematic sampling method among the schools located in the central towns of Izmir. The data of the study were collected through a two-tier Test for Polygonal Misconceptions (TFPM) and an Interview Form. There are 15 items on TFPM and KR-20 reliability coefficient was found .74. The answers of students and explanations were categorized and their misconceptions were investigated. The interview form was used to determine the possible reasons for those misconceptions. The data obtained from the TFPM were analyzed through percentage and frequency, while the data collected with the interviews were analyzed through content analysis. According to the findings of the study, it was concluded that students had various misconceptions on the characteristics, classification and definition of polygonal concepts and determining relations among these concepts. It was found that factors aroused from students' own attributes, teachers, materials, tools and several linguistic properties underlie these misconceptions.
\end{abstract}

Keywords: Mathematics, geometry, polygons, concepts, misconceptions, the reasons of misconceptions 


\section{Giriş}

Matematik, insanlığın gelişiminde ve bu gelişimle yakından ilgisi olan her türlü bilim dalında göz ardı edilemez bir yere ve öneme sahip olan bilim dalıdır (Çelik, 1996). Her geçen gün önemi daha da artan matematik, mantıksal bir düşünme sistemi olmasının yanında varlıklar arasında yer alan ilişkileri açıklamamızı sağlayan bir iletişim aracıdır (Aksu, 1991). İnsanların matematiği günlük hayatlarında kullanabilmeleri, matematikle ilgili bilgi ve becerilerini artırabilmeleri ve dünyayı daha iyi anlamlandırabilmeleri, ancak etkili bir matematik öğretimi ile gerçekleştirilebilir. Günümüzde bireyler yaşamın hemen her alanında matematikle yüz yüze gelmekte ve matematikle ilgili kavramları kullanma ihtiyacı doğmaktadır. Bu ihtiyacın giderilebilmesi ise sayılarla ilgili beceriler, tahmin etme stratejileri ve verilerin analizi gibi pek çok matematiksel kavramla ilişkilidir (Duman, 2006). Bu nedenle matematikle ilgili davranışlar okul öncesinden başlayarak yükseköğretim programlarına kadar bütün düzeylerde ve alanlarda yer alırlar (Baykul, 2005). Çünkü matematik, toplumların dünyayı düzenleme ve organize edebilmeleri için sahip olunması gereken en güçlü araç olarak görülmekte ve bu nedenle de matematik öğretimi toplumların vazgeçilmez temel öğretilerinden biri haline gelmektedir (S1vac1, 2003).

Matematik öğretiminin daha etkili gerçekleştirilebilmesi amacıyla çağın gerekliliklerine uygun olarak matematik öğretim programlarında düzenleme ve değişiklikler yapılmaktadır. Ülkemizde uygulanan matematik öğretim programı da yapılandırmacı yaklaşımın temele alındığı bir program niteliğinde olup, öğrencinin var olan bilgilerinin üzerine yeni bilgilerini inşa etmesi amacını taşımaktadır (Erden ve Akman, 2004). Bu bağlamda, yenilenen matematik öğretim programı öğrencilerin anlamsız ve ilişkisiz işlemleri veya formülleri ezberlemek yerine, kavramlar arasında neden-sonuç ilişkilerinin kurulduğu ve kavramsal anlamanın ön plana çıktığı bir öğretimi hedeflemektedir (Özmantar, Bingölbali ve Akkoç, 2013). Kavramsal yaklaşım, matematikle ilgili bilgilerin kavramsal temellerinin oluşturulmasına daha çok zaman ayırmayı; böylece kavramsal ve işlemsel bilgi ve beceriler arasında ilişkiler kurmayı gerektirmektedir (Milli Eğitim Bakanlı̆̆ı, 2013).

Günümüz matematik öğretim programlarında önceki programlardakinin aksine işlemsel becerilerin değil kavramsal öğrenmelerin daha ön planda tutulmasının en önemli nedeni şüphesiz ki kavramların öğrenmeye olan katkılarıdır (Dane, 2008). Kavramlar, insanoğlunun düşünme sürecine katkı sağlayan zihinsel araçlar olarak tanımlanmakta ve bireyin hem bir grup varlık, olay, fikir ve süreçleri diğer gruplardan ayırt etmesini sağlamakta hem de diğer gruplarla aralarında ilişki kurmasına yardımcı olmaktadır (Senemoğlu, 2013). Bireylere göreli 
Ege Eğitim Dergisi 2017 (18) 1: 83-104

Çokgenlerle İlgili Kavram Yanılgıları ve Olası Nedenler

olarak kalıcı bilgi sistemi sağlayan kavramlar, aynı zamanda sahip olunan bilgi sistemlerini genişletmeye de yardımcı olurlar (Erden ve Akman, 2004). Ayrıca çevrenin düzene girmesini, algısal ilişkilerin derinlik kazanmasını, düşüncenin netlik kazanmasını ve özellikle de öğrenme sürecinin kolaylıkla gerçekleşmesini sağlamada kavramların rolü büyüktür (Elliott, Kratochwill, Littlefield Cook ve Travers, 2000). İnsan zihninde anlam kazanan obje ve olguların farklı veya ortak niteliklerini yansıtan kavramlar, öğrenme için büyük öneme sahiptirler (Ülgen, 2001). Anlamlı öğrenmenin gerçekleşmesi için ilk adım olarak görülen kavramların öğretimi, öğretim sürecinin en temel adımlarından birini oluşturur (Temizkan, 2011). Kavram öğretimi ile bilgilerin yeni durumlara uygulanması ve öğrenilen bilgilerin daha kalıcı olması sağlanmakta, bu sayede öğrenmeye karşı isteklilik artmaktadır (Ayas, Karamustafaoğlu, Cerrah ve Karamustafaoğlu, 2001).

Öğrenme üzerinde büyük öneme sahip olan kavramların öğrenilmesinde bazen bir takım zorluklar yaşanabilmekte, bazı kavramlar ya hiç öğrenilememekte ya da yanlış öğrenilmektedir (Yılmaz ve Çolak, 2011). Kavramların öğrenilmesinde engel teşkil eden bu zorlukların başında kavram yanılgıları olarak adlandırılan yapılar gelmektedir (Byrd, McNeil, Chesney ve Matthews, 2015). Kavram yanılgılarının alanyazında değişik şekillerde tanımlamaları yapılmıştır. "Öğrenenlerin genellikle bilgi eksikliklerinden dolayı yanlış anlamlandırmalar yapmalarıyla ortaya çıkan hatalı düşünceler ya da yorumlamalar" (Ojose, 2015), "bireyin doğru kabul ettiği birçok beceriyi göstermede kaynak olarak kullandığı yanlış kavramlar ya da kavramlaştırmalar" (Meşeci, Tekin, Karamustafaoğlu, 2013), "bir alanın uzmanları tarafından genel kabul görmüş kavram ya da algılarla çelişen kavramlar" (Zembat, 2013) kavram yanılgıları için yapılmış tanımlamalardan bazılarıdır.

Öğretmenlerin hiçbir kavram yanılgısının oluşmadığı bir öğretim yapmaları neredeyse imkânsızdır (Koklu ve Topcu, 2012). Dolayısıyla öğrencilerin bilgiyi doğru öğrenip öğrenmediklerini belirlemede, oluşan yanılgıların en kısa zamanda teşhis edilmesi ve giderilmesi büyük önem taşır (Osborne ve Gilbert, 1980; Özdeş ve Elitok Kesici, 2015; Resnick ve diğg., 1989). Çünkü oluşan her kavram yanılgısı bireyin zihninde diğer birçok kavramla ilişkilendirilmekte ve giderek daha karmaşık bir hal alabilmektedir (Comins, 1998). Öyle ki erken yaşlarda oluşan kavram yanılgıları oldukça yaygın ve kalıcı bir özellik taşımakta, hatta öğrencilerin yetişkinlik hayatlarında bile zorluklara yol açmaktadır (Stacey ve diğ., 2001).

Yapılan çalışmalarda çoğunlukla soyut kavramlardan oluşan, ardışık ve yığmalı bir bilim dalı olan matematik gibi alanlarda kavram yanılgılarının sıklıkla görüldüğü ortaya çıkmıștır (Ercan, 2010). Matematiksel kavramlar arasında yer alan ön-koşul ilişkilerinin yüksek düzey- 
de olması, oluşan kavram yanılgılarının sonraki kavramlarda da ortaya çıkmasına ve giderek çoğalmasına yol açmaktadır (Türkdoğan, Güler, Bülbül ve Danişman, 2015). Her ne kadar öğrencilerin yeni bir kavramı önceki bilgileriyle ilişkilendirmesinin öğrenmeyi daha güçlü hale getirdiği düşünülse de, öğrencilerin ön öğrenmelerinde yer alan kavram yanılgıları bu duruma olumsuz etki etmektedir. Bir diğer ifadeyle, öğrencilerin daha önce öğrendiği kavramlarda yer alan yanılgılar, yeni öğrenilen bilgilerin de kavram yanılgısı şeklinde ortaya çıkmasına yol açmaktadır (Stafylidou ve Vosniadou, 2004). Özellikle matematikte, öğrencilerin önceki deneyimlerinden yola çıkarak sığ bilgiler üretmeleri ve bu bilgiyi karşılaştıkları problem durumlarına genellemeleri sonucu birçok kavram yanılgıları oluşabilmektedir (Byrd ve diğ., 2015). Kavram yanılgılarının tespit edilip bu yanlışı gidermeye yönelik yapılan öğretim ise öğrencilerin sadece hatalarını gidermekle kalmayıp doğru bilgiyi öğrenmelerini kolaylaştırmakta ve kalıcı öğrenmenin gerçekleşmesini sağlamaktadır (Stefanich ve Rokusek, 1992). Ayrıca yapılan araştırmalar kavram yanılgılarının doğasını ve yanılgıya yol açan etmenleri bilen öğretmenlerin öğretimi planlarken daha uygun stratejiler üretebildiklerini de göstermektedir (Ojose, 2015).

$\mathrm{Bu}$ araştırmada öğrencilerin matematiğin özel bir alanı olan geometride yer alan çokgenler konusuyla ilgili kavram yanılgılarının belirlenmesi ve bu yanılgıların nedenlerinin ortaya çıkarılması amaçlanmıştır. Bu amaç doğrultusunda araştırma sorusu "Yedinci sınıf öğrencilerinin çokgenlerin özelliklerine ve sınıflandırılmasına ilişkin kavram yanılgıları ve bu yanılgıların temel nedenleri nelerdir?” şeklinde organize edilmiştir. Bu çalışmanın matematiğin alt dalı olan geometrinin bir konusu olan çokgenler üzerinde yürütülmesinin temel nedeni alanyazında bu konuda kavram yanılgılarının sıklıkla yaşandığına ilişkin bulgulardır (Türnüklü ve Berkün, 2013). Alanyazında çokgenlerle ilgili kavram yanılgılarının erken çocukluk döneminden başlayarak alan eğitimcisi olarak çalışan bireylere kadar geniş bir yelpazede yaşandığını gösteren bulgulara rastlanılmaktadır. Bu çalışmanın alanda sıklıkla karşımıza çıkan kavram yanılgılarının neler olduğunun belirlenmesinin yanı sıra bunların nedenlerini ortaya koyması açısından önemli olduğu düşünülmektedir. Elde edilen sonuçlar doğrultusunda öğretim uygulamalarını gerçekleştirmekte olan öğretmenlere çokgenler konusunun öğretiminde, var olan öğrenci yanılgılarını giderici veya yeni kavram yanılgılarının oluşmasını önleyici öğrenme ortamları hazırlamada ve geometri öğretimi ile ilgili ileride yapılacak çalışmalarda yanılgıların önlenmesine yönelik düzenlemelerin yapılmasında 1şık tutulacağına inanılmaktadır. 


\section{Yöntem}

\section{Araştırma Modeli}

$\mathrm{Bu}$ araştırmada yedinci sınıfta öğrenim gören öğrencilerin çokgenlerle ilgili kavram yanılgılarını ve bu yanılgıların nedenlerini belirlemek amacıyla karma yöntem araştırma türlerinden biri olan ardışık açıklayıcı desen kullanılmıştır. Ardışık açıklayıcı desen, toplanan nicel verilerin açıklanması veya tamamlanmasına ihtiyaç duyulduğunda kullanılan bir araştırma türüdür (Fraenkel, Wallen ve Hyun, 2012). Başka bir deyişle elde edilen nicel verilerin sonuçlarını geliştirmek ve düzeltmek amacıyla nitel verilerden yararlanılır. $\mathrm{Bu}$ durumda nicel verilerin toplanmasını nitel verileri toplama işlemi takip eder. Toplanan nicel ve nitel veri ayrı ayrı analiz edilir (Creswell, 2007). Bu çalışmada da öncelikle nicel veriler toplanmış ve analiz edilmiş; ardından da öğrencilerle yapılan görüşmeler yoluyla nitel veriler elde edilmiş ve nicel verilerin yorumlanmasında kullanılmıştır.

\section{Evren ve Örneklem.}

Araştırmanın evreni İzmir ili merkez ilçelerinde bulunan okullarda öğrenim gören yedinci sınıf öğrencilerinden oluşmaktadır. Araştırmanın örneklemi ise bu ilçelerde bulunan okullar arasından sistematik örnekleme yöntemiyle belirlenen okullarda 2013-2014 eğitim öğretim yılında öğrenim gören 7. sınıf 424 öğrenciden oluşmaktadır. Sistematik örnekleme yoluyla belirlenen okullarda öğrenim gören 855 yedinci sınıf öğrencisine ÇKYBT uygulanmış, ancak soruların çoğunluğuna açıklama yazmayan, birden fazla seçeneği işaretleyen, hiçbir soruyu çözmeyen ya da test kâğıdına anlaşılamayan yazılar yazan öğrenciler tespit edilerek yanıtları değerlendirmeye alınmamıştır. Değerlendirmeye alınan 424 öğrencinin \% 56'sı (238) kadın, \% 44'ü (186) erkek öğrencilerden oluşmaktadır.

Araştırmanın nitel verilerini elde etmek amacıyla ölçüt örnekleme kullanılarak 2'si erkek 3’ü kadın olmak üzere toplam 5 katılımcı belirlenmiştir. Ölçüt örnekleme, araştırmacı tarafından önceden belirlenen bir dizi ölçütü karşılayan bütün durumların çalışılması şeklinde gerçekleştirilir (Yıldırım ve Şimşek, 2011). Bu amaçla öncelikle nicel veriler toplanıp analiz edilmiş, ÇKYBT'deki soruların yarıdan fazlasında kavram yanılgısı olan öğrenciler tespit edilerek bu öğrencilerden görüşme yapmayı kabul edenler arasından katılımcılar belirlenmiştir. Katılımcıların hepsinin farklı okullardan olmasına dikkat edilmiş; görüşmelere içtenlikle katılmalarını sağlamak için isimleri, okulları, sınıfları belirtilmemiş, kodlama yapılmış ve aslı araştırmacı tarafından saklı tutulmuştur. Araştırmacı öğretim sürecine doğrudan dahil olma- 
Ege Eğitim Dergisi 2017 (18) 1: 83-104

Çokgenlerle İlgili Kavram Yanılgıları ve Olası Nedenler

mış, verilerin toplanması aşamasında devreye girmiştir. Bu nedenle araştırmacının öğrenenler üzerindeki etkisi minimize edilmeye çalışılmıştır.

\section{Veri Toplama Araçları}

Araştırmada veri toplama aracı olarak araştırmacı tarafından geliştirilen iki aşamalı Çokgenler Kavram Yanılgılarını Belirleme Testi (ÇKYBT) ve Görüşme Formu kullanılmıştır. ÇKYBT'de yedinci sınıf matematik öğretim programında yer alan geometri öğrenme alanıyla ilgili tüm kazanımları ölçen 15 madde yer almaktadır. Testin hazırlanması sürecinde belirlenen kazanımlardan her birini ölçecek nitelikte en az 3 madde yazılmış ve toplam 47 maddeden oluşan bir deneme formu hazırlanmıştır. Bu form, deneme uygulamasından önce program geliştirme alanından iki, matematik eğitimi alanından üç, ölçme ve değerlendirme alanından iki, Türkçe eğitimi alanından bir uzman ve MEB'de görev yapan üç matematik öğretmeni olmak üzere 11 eğitimcinin görüşlerine sunulmuş, alınan geri bildirimler doğrultusunda gerekli düzenlemelere gidilmiştir. Yapılan düzenlemelerin ardından 47 maddelik deneme formu, bu konuları daha önce öğrenmiş olan 343 öğrenciye uygulanmış ve madde analiz programı kullanılarak her bir maddeye ait ayırt edicilik ve güçlük indeksleri ile testin güvenirlik katsayısı hesaplanmıştır. Deneme formunda yer alan maddeler arasından her kazanımı ölçecek şekilde yüksek ayırt edicilik indeksine sahip ve orta güçlükte olan 15 madde seçilerek nihai test oluşturulmuştur. Nihai testin KR-20 güvenirlik katsayıs1 .74, ortalama güçlüğü .37, standart sapması 3.26 ve aritmetik ortalaması 5.52 olarak elde edilmiştir. Nihai form oluşturulduktan sonra her bir madde için "Cevabınızın nedenini açıklayınız” şeklinde öğrencilerin çoktan seçmeli sorulara açıklama yapmaları istenen bir bölüm eklenmiştir.

Araştırmada kullanılan bir diğer ölçme aracı olan yarı yapılandırılmış görüşme formu, ÇKYBT’nin öğrencilere uygulanmasının ardından belirlenen kavram yanılgılarının temel nedenlerini ortaya koyabilmek için araştırmacı tarafından geliştirilmiştir. Görüşme formunda öğrencilerin geometri kavramlarının özellikleri, aralarındaki ilişkiler, öğrenme ve öğretme esnasında karşılaşılan durumlar hakkında görüşlerini öğrenmek amacıyla hazırlanmış açık uçlu 13 soru yer almaktadır. Uygulama öncesinde sorular eğitim programları ve öğretim alanında çalışan üç akademisyenin görüşüne sunulmuş ve gelen dönütler doğrultusunda gerekli düzeltmeler yapılarak forma son hali verilmiştir.

\section{Verilerin Toplanması}

Örneklemde yer alan okullarda öğrenim gören yedinci sınıf öğrencilerine, çokgenler konusunun öğretiminden hemen sonra ÇKYBT uygulanmıştır. Uygulamalar araştırmacı tarafından 
Ege Eğitim Dergisi 2017 (18) 1: 83-104

Çokgenlerle İlgili Kavram Yanılgıları ve Olası Nedenler

gerçekleştirilmiş ve testi cevaplamaları için öğrencilere 40 dakika süre verilmiştir. Daha sonra ÇKYBT’den elde edilen verilerden yola çıkılarak belirlenen öğrencilerle yüz yüze görüşmeler yapılmıştır. Görüşmeler 15-35 dakika arası zaman diliminde yapılmış ve ses kayıt cihazı yardımıyla kaydedilmiştir. Kayıtlar öğrencilerin ifadelerini ya da herhangi bir sözcüğü tekrar dinlemede ve alıntı yapmada oldukça kolaylık sağlamıştır.

\section{Verilerin Analizi}

Verilerin analizinde öncelikle ÇKYBT’den elde edilen veriler analiz edilmiş, ardından öğrenci görüşmelerinden elde edilen verilerin analizine geçilmiştir. ÇKYBT'den elde edilen verilerin analizi yapılırken öncelikle testin çoktan seçmeli olan ilk aşaması için verilen yanıtlar “Doğru”, “Yanlış” ve “Yanıt Yok” biçiminde kodlanmış, ardından frekans ve yüzdeleri hesaplanmıştır. Kavram yanılgılarının da belirlendiği testin açık uçlu olan ikinci aşamasına verilen öğrenci yanıtları Karataş (2002) ve Coştu'nun (2002) kullanmış olduğu kategorilere benzer şekilde ele alınmıştır. Ancak bu kategorilere ek olarak, araştırmacı tarafından "Bilgi Eksikliği”" şeklinde yeni bir kategori daha eklenmiştir. Testte yer alan maddelerin ikinci aşamasına "bilimsel olarak yanlış olmasa da eksik bilgi içeren yanıtlar" vermiş olan ve aynı maddelerin ilk aşamasına da bu eksik bilgiler nedeniyle yanlış cevap verdiği düşünülen öğrenci yanıtları bu kategoride değerlendirilmiştir. Verilen yanıtlara göre öğrencilerin anlama düzeyleri ve puanlama kategorileri Tablo 1'de gösterilmiştir.

Tablo 1. ÇKYBT'nin analizinde kullanılan kategoriler ve anlama düzeyleri

\begin{tabular}{|c|c|}
\hline Anlama Düzeyleri & Puanlama Kategorileri \\
\hline $\begin{array}{l}\text { 1.Tam Anlama } \\
\text { (I. Aşama: Doğru cevap + II. Aşama: Doğru Gerekçe) }\end{array}$ & $\begin{array}{l}\text { - Geçerliliği olan cevabın bütün yönlerini } \\
\text { içeren cevaplar }\end{array}$ \\
\hline $\begin{array}{l}\text { 2. Kısmen Anlama } \\
\text { (I. Aşama: Doğru cevap + II. Aşama: Kısmen Doğru } \\
\text { Gerekçe) }\end{array}$ & $\begin{array}{l}\text { - Geçerli olan cevabın bir yönünü içeren } \\
\text { fakat bütün yönlerini içermeyen cevaplar } \\
\text { - Geçerli cevabın bazı yönleriyle birlikte } \\
\text { bazı yanlış anlamaları içeren cevaplar }\end{array}$ \\
\hline $\begin{array}{l}\text { 3. Bilgi Eksikliği } \\
\text { (I. Aşama: Yanlış cevap + II. Aşama: Eksik Gerekçe) }\end{array}$ & $\begin{array}{l}\text { - Eksik bilgiden kaynaklanan yanlış cevap- } \\
\text { lar }\end{array}$ \\
\hline $\begin{array}{l}\text { 4. Kavram Yanılgısı } \\
\text { (I. Aşama: Yanlış cevap + II. Aşama: Yanlış Gerekçe) }\end{array}$ & $\begin{array}{l}\text { - Bilimsel olarak doğru olan bilgilerle çeli- } \\
\text { şen cevaplar }\end{array}$ \\
\hline $\begin{array}{l}\text { 5. Boş } \\
\text { (I. Aşama: Doğru cevap + II. Aşama: Gerekçe yok) } \\
\text { (I. Aşama: Yanlış cevap + II. Aşama: Gerekçe yok) } \\
\text { (I. Aşama: Yantt yok + II. Aşama: Gerekçe yok) }\end{array}$ & $\begin{array}{l}\text { - İlgisiz, açık olmayan cevap verme } \\
\text { - Boş bırakma } \\
\text { - "Bilmiyorum, anlamadım" şeklinde ce- } \\
\text { vaplama } \\
\text { - Soruyu aynen tekrarlama }\end{array}$ \\
\hline
\end{tabular}


Tablo 1'de de görüldüğü gibi, “Tam Anlama” düzeyi, ilk aşamanın doğru cevaplandığg ve ikinci aşamada da bu cevabın bütün yönlerini içeren doğru bir açıklamanın yapıldığı öğrenci yanıtları olarak sınıflandırılmıştır. "Kısmen Anlama" düzeyi, ilk aşamanın doğru yanıtlandığı ancak ikinci aşamada cevabın bütün yönlerinin yer almadığı öğrenci yanıtları şeklinde sınıflandırılmıştır. "Bilgi Eksikliğgi" düzeyinde yer alan öğrenciler soruların ilk aşamasına yanlış yanıt vermiş ve ikinci aşamada eksik bilgi içeren yanıtlar vermişlerdir. "Kavram Yanılgısı" olduğu düşünülen öğrenciler ise soruların ilk aşamasına yanlış yanıt vermiş, ikinci aşamada da bu yanlışı destekler nitelikte bilimsel olarak yine yanlış açıklamalar yapmışlardır. İkinci aşamanın yanıtsız bırakıldığı öğrenci yanıtları ise "Boş" olarak ifade edilmiş ve değerlendirmeye alınmamıştır.

Öğrencilerle yapılan görüşmeler, araştırmacı tarafından yazıya aktarılarak incelenmiştir. Verilerin çözümlenmesinde nitel veri analizi yöntemlerinden olan içerik analizi kullanılmıştır. Elde edilen nitel verilerin geçerliğini artırmak amacıyla, veriler yazıya aktarıldıktan sonra araştırmacıyla birlikte iki matematik öğretmeni tarafından da incelenmiş, ortak görüşler doğrultusunda kodlar oluşturulmuştur. Görüşmeler kavram yanılgılarının öğrenciden, öğretmenden, kullanılan araç gereçlerden ve dilin özelliklerinden kaynaklanan nedenler şeklinde dört tema altında incelenmiştir. Daha sonra bu temaları oluşturan kodlar ve alt kodlara ait öğrencilerin yanıtları ayrıntılı olarak incelenmiş ve örneklendirilmiştir.

\section{Bulgular}

Araştırma sonucu elde edilen veriler 1şığında öğrencilerin ÇKYBT'de yer alan maddelerin her iki aşamasına vermiş oldukları yanıtlar ayrı ayrı incelenmiş, bu yanıtlara göre öğrencilerin anlama düzeyleri 5 kategori altında belirlenmiştir. Öğrencilerin ilk aşamaya verdikleri yanıtlara ait betimsel istatistikler Tablo 2'de görülürken, her iki aşamanın birlikte değerlendirilmesiyle elde edilen, kavram yanılgısı veya bilgi eksikliğine sahip öğrenci yüzdeleri ile kısmen ya da tam anlamaya sahip öğrenci yüzdeleri ise Tablo 3'de gösterilmiştir.

Tablo 2. Testte yer alan maddelerin ilk aşamasına verilen yanitlara ait betimsel istatistikler

\begin{tabular}{cccc}
\hline Madde no & $\begin{array}{l}\text { Doğru } \\
\text { (\%) }\end{array}$ & $\begin{array}{l}\text { Yanlış } \\
\text { (\%) }\end{array}$ & Yanıt Yok (\%) \\
\hline 1 & 66.3 & 33 & 0.7 \\
2 & 37.0 & 60.6 & 2.4 \\
3 & 42.9 & 54 & 3.1 \\
4 & 59.7 & 38.2 & 2.1 \\
5 & 35.4 & 56.8 & 7.8 \\
6 & 37.0 & 57.7 & 5.2 \\
\hline
\end{tabular}




\begin{tabular}{cccc}
\hline 7 & 52.4 & 43.3 & 4.2 \\
8 & 29.5 & 62 & 8.5 \\
9 & 46.0 & 44.3 & 9.7 \\
10 & 24.5 & 68.3 & 7.1 \\
11 & 24.8 & 64.1 & 11.1 \\
12 & 48.1 & 34.4 & 17.5 \\
13 & 14.4 & 60.8 & 24.8 \\
14 & 48.1 & 35.6 & 16.3 \\
15 & 46.5 & 42.2 & 11.3 \\
\hline
\end{tabular}

Tablo 2'ye göre çoktan seçmeli ilk aşamasına en yüksek oranda doğru yanıt verilen maddeler sırasıyla 1, 4, 7, 12 ve 14. maddeler olurken, en yüksek oranda yanlış yanıt verilen maddeler sirasıyla 10,11, 13, 2 ve 5. maddeler olmuştur. Testte yer alan on beş maddenin sekizine $(2,3,5,6,8,10,11$ ve 13 . maddeler) öğrencilerin yarıdan fazlasının yanlış yanıt verdiği görülmektedir. Öğrencilerin en yüksek oranda yanıtsız bıraktığı maddeler ise sırasıyla 13, 12 , 14,15 ve 11. maddeler olmuştur.

Tablo 3. Maddelerin her iki aşamasına verilen yanıtlara göre anlama düzeyleri

\begin{tabular}{|c|c|c|c|c|c|}
\hline $\begin{array}{c}\text { Madde } \\
\text { No }\end{array}$ & $\begin{array}{l}\text { Boş } \\
\text { (\%) }\end{array}$ & $\begin{array}{c}\text { Kavram } \\
\text { Yanılgısı } \\
(\%)\end{array}$ & $\begin{array}{c}\text { Bilgi Ek- } \\
\text { sikliği } \\
(\%)\end{array}$ & $\begin{array}{c}\text { Kismen } \\
\text { Anlama } \\
(\%)\end{array}$ & $\begin{array}{c}\text { Tam } \\
\text { Anlama } \\
(\%)\end{array}$ \\
\hline 1 & 37.0 & 19.6 & 0.7 & 34.9 & 7.8 \\
\hline 2 & 20.3 & 40.3 & 12.3 & 23.8 & 3.3 \\
\hline 3 & 26.2 & 40.1 & 2.1 & 23.3 & 8.3 \\
\hline 4 & 21.7 & 14.9 & 12.0 & 42.5 & 9.0 \\
\hline 5 & 33.3 & 40.3 & 0.9 & 17.0 & 8.5 \\
\hline 6 & 32.3 & 24.1 & 12.5 & 23.6 & 7.5 \\
\hline 7 & 23.8 & 30.0 & 0.2 & 21.5 & 24.5 \\
\hline 8 & 36.6 & 40.1 & 2.1 & 11.8 & 9,4 \\
\hline 9 & 36.8 & 25.9 & 1.2 & 8.0 & 28.1 \\
\hline 10 & 37.5 & 37.7 & 7.5 & 13.2 & 4.0 \\
\hline 11 & 41.5 & 43.2 & 0 & 0.2 & 15.1 \\
\hline 12 & 55.9 & 9.0 & 0.5 & 27.4 & 7.3 \\
\hline 13 & 67.0 & 25.0 & 2.1 & 0.9 & 5.0 \\
\hline 14 & 61.8 & 5.4 & 1.2 & 27.6 & 4.0 \\
\hline 15 & 46.7 & 18.2 & 2.8 & 21.5 & 10.8 \\
\hline
\end{tabular}


Tablo 3'e göre öğrencilerin en fazla 2, 3, 5, 8 ve 11. maddelerde kavram yanılgıları olduğu görülmektedir. Her iki aşamaya verilen yanıtlara göre tam anlama gösteren öğrencilerin en fazla olduğu maddeler sırasıyla 9, 7, 11 ve 15 şeklindedir. Birinci veya ikinci aşamadan herhangi birinin en yüksek oranda yanıtsız bırakıldığı maddeler ise sırasıyla 13, 14, 12, 15 ve 11 . maddelerdir.

Tablo 2 ve Tablo 3’de verilen bilgilere göre maddelerin yanlış yanıtlanma yüzdesi ile kavram yanılgısı yüzdesinin farklı olduğu görülmektedir. Örneğin Tablo 3'e göre 11. maddenin ilk aşamasını yanlış yanıtlayan öğrenciler \% 64,1 iken, aynı maddede kavram yanılgısı olduğu belirlenen öğrencilerin oranı ise \% 43,2'dir. Benzer şekilde 13. maddenin ilk aşaması öğrencilerin \% 60,8'i tarafından yanlış yanıtlanırken, bu madde ile ilgili öğrencilerin sadece \% 25'inde kavram yanılgısı olduğu saptanmıştır. Bu sonuçlardan hareketle öğrencilerin yanlış yanıtlanan her soruda kavram yanılgısı yaşamadığı, dolayısıyla çeşitli nedenlerden dolayı (örneğin bilgi eksikliği) öğrencilerin yanlış seçeneklere yönelebildikleri söylenebilir.

Kavram yanılgısı olduğu belirlenen öğrencilerin sorunun ikinci aşaması olan "Cevabınızın nedenini açıklayınız” bölümüne verdikleri yanıtlara bakıldığında ise çeşitli yanılgılara düştükleri görülmüştür. Örneğin birinci maddede öğrencilerin dışbükey çokgenlerin özelliklerini tanımlarken Ö 68 “Dışbükeyler köşeleri içine doğru bükülenlerdir” ifadesini kullanırken, Ö 191 ise "Dışbükey olabilmesi için en az bir köşegeninin dışarıda olması gerekir" ifadesini kullanmıştır. İkinci maddeye verilen yanıtlara göre ise Ö 284'ün “Paralelkenarın köşegenleri her zaman 90’'lik açlyla kesişir” ve Ö 349'un “Karenin ve eşkenar dörtgenin tüm açıları birbirine eşittir, yamuğun ise hiçbir açısı eşit olamaz" şeklindeki ifadeleri, bu öğrencilerin ilgili konuda kavram yanılgıları olduğunu işaret etmektedir. Benzer şekilde, dikdörtgenin özelliklerini ayırt etme ile ilgili olan üçüncü maddede de Ö 10 ve Ö 19’un “dikdörtgenin karşılıklı kenarları paralel değildir, paralel olsaydı dikdörtgen değil paralelkenar olurdu, sadece paralelkenarın karşılıklı kenarları paraleldir, dikdörtgenin olamaz” şeklindeki ifadeleri, öğrencilerin bu konuda kavram yanılgıları olduğunu göstermektedir.

Karenin özelliklerini belirleme ile ilgili olan dördüncü maddeye Ö 18 ve Ö 338’in “karenin dlş açıları toplamı 90'dir” ve Ö 224’ün “Kare düzgün çokgen değildir” ş̧eklinde verdikleri yanıtlar, öğrencilerin kavram yanılgıları olduğunu göstermektedir. Paralelkenarın özelliklerini ayırt etme ilgili olan beşinci maddeye Ö 67'nin vermiş olduğu 'Paralelkenarın karşılıklı açıları ve kenarları eşit olduğu için köşegenleri dik kesişir" yanıtı, bu öğrencinin kavram yanılgısı olduğunu işaret etmektedir. Yamukla ilgili özelliklerin belirlenmesini amaçlayan altıncı 
soruda ise Ö 257, Ö 65, Ö 238 ve Ö 48'in “Yamuğun açılarından biri $90^{0}$ olamaz” şeklindeki yanıtları, bu öğrencilerin ilgili kavram hakkında yanılgıları olduğunu göstermektedir.

Genel olarak dörtgenlerin kenar, açı ve köşegen özelliklerine göre sınıflandırılması ile ilgili bilgi ve becerileri ölçen sekizinci maddeye Ö 41'in yanıtı “Eşkenar dörtgenin köşegenleri her zaman açıortay değildir" şeklinde olurken, Ö 70, Ö 75, Ö 93 ve Ö 324'ün yanıtları ise “Sadece dikdörtgenin köşegenleri her zaman açıortaydır" şeklinde olmuştur. Verilen bu yanıtlar, öğrencilerin ilgili konuda kavram yanılgıları olduğunu göstermektedir. Üçgenlerin açı, kenar ve köşegen özelliklerine sınıflandırılması ile ilgili kazanımların ölçüldüğü bir diğer madde ise Ö 15, Ö 21, Ö 30, Ö 39 ve Ö 41’in “ikkizkenar üçgenlerin eşit olan açıları her zaman taban üzerinde yer alır" şeklinde bir kavram yanılgıları olduğunu ortaya koymaktadır. Dörtgen çeşitleri arasındaki ilişkilerin belirlendiği bir diğer maddeye Ö 115, Ö 158, Ö 170, Ö 194, Ö 69 ve Ö 60’1n “Kare ve eşkenar dörtgenin tüm özellikleri aynıdır, kare eşkenar dörtgenin diğer adıdır” ve Ö 341'in “Dikdörtgenin tüm kenarları eşittir, ancak paralelkenarın tüm kenarları eşit olamaz” şeklindeki yanıtları, öğrencilerin bu konuda kavram yanılgıları olduğunu göstermektedir.

Testte yer alan ve çokgenlerin açılarını hesaplama ile ilgili kazanımları ölçen maddeye verilen yanıtlara göre öğrencilerin "ikizkenar üçgenlerin ikiz açılarının her zaman taban üzerindeki iki açı olması gerektiği, dikdörtgenin bir iç açısının 90'den büyük olabileceği” gibi kavram yanılgıları olduğu söylenebilir. Üçgenlerin kenar ve çevre uzunluklarını hesaplama ile ilgili olan bir diğer maddede ise, öğrencilerin "üçgenin çevre uzunluğu iki kenarın çarpımıyla bulunabileceğgi" şeklinde kavram yanılgıları olduğu ortaya çıkmıştır. Ayrıca aynı maddeye verilen yanıtlara göre, öğrencilerin açı ölçümleri ile kenar ölçümlerini ayırt edemedikleri, üçgenin çevre uzunluğunu hesaplarken açıların değerleri ile kenar uzunluklarını topladıkları, dolayısıyla bu konuda kavram yanılgıları olduğu söylenebilir. Üçgensel ve dörtgensel bölgelerin alanlarını hesaplama ile ilgili maddelere verilen yanıtlara göre öğrencilerin "paralelkenarın alanının karşılıklı iki kenarın uzunluğunun çarpımına eşit olduğu”; "bir üçgende hipotenüsün diğer iki kenarın uzunluğundan kısa olabileceği”; "taban uzunluğu ve yükseklikleri eşit olan üçgenlerin alanlarının farklı olabileceğ $i$ ” şeklinde kavram yanılgıları olduğu görülmektedir. Düzgün çokgenlerin ayırt etme ile ilgili olan maddeye verilen yanıtlara göre ise bazı öğrencilerin "tüm dikdörtgenlerin birer düzgün çokgen olabileceği”; “düzgün çokgen olabilmesi için açıların önemli olmadığl, kenarlar eşitse düzgün çokgen olabileceğ $i$ ” şeklinde kavram yanılgıları olduğu söylenebilir. 
Belirlenen bulgulara bağlı olarak yapılan görüşmelerden kavram yanılgılarının öğrencilerin kendisinden, öğretmenlerden, kullanılan materyallerden ve konuşulan dilin özelliklerinden kaynaklandığı belirlenmiştir. Öğrencilerden kaynaklanan nedenler arasında konuya ilişkin yeterli bilgiye sahip olmamaları, aşırı genelleme yapmaları, bir kavramın tanımına ait gerekli ve yeterli şartları göz ardı etmeleri, matematiksel dili kullanmada zorlanmaları ve kavramlar arasındaki ilişkileri doğru kuramamaları neticesinde kavram yanılgıları ortaya çıktığı bulgusu elde edilmiştir. Örneğin Ö 1 ve Ö 2'nin “Kare ve eşkenar dörtgenin tüm kenarları ve açıları eşittir. Her ikisinin de eşit uzunlukta iki köşegeni vardır. Kareyi yana çevirdiğimizde eşkenar dörtgen elde edilir" şeklindeki açıklamalarından, bu öğrencilerin iki kavram arasındaki ilişkiyi kuramadıkları, kavramlar hakkında bilgi eksikliklerinin olduğu anlaşılmaktadır.

Kavram yanılgılarına neden olan bir diğer durum ise öğretmenlerin geometri kavramlarının öğretiminde uygun olmayan örnekler ve yanlış benzetmeler kullanması, sadece prototip örnekler üzerinden konuların öğretilmesi, özellikle somut materyal kullanmada yeterli olmamaları şeklinde belirlenmiştir. Öğrencilerin verdikleri yanıtlara ve geometrik şekillere ait yaptıkları çizimlere göre, neredeyse tüm geometrik şekillerin sınıfta prototip örnekler üzerinden öğretildiği bulgusu elde edilmiştir. Ayrıca paralelkenar kavramı için "ev çatısı”, eşkenar dörtgen kavramı için "baklava dilimi” gibi örneklerin kullanılması, bu örneklerin farklı şekilleriyle karşılaşan öğrencilerde kavram yanılgısı oluşturabileceği bulgusunu ortaya çıkarmıştır.

Öğrencilerin verdikleri cevaplara referans olarak ders kitaplarını ve bu kitaplarda yapılan tanımlamaları, şekilleri göstermeleri de kavram yanılgılarına sebep olmaktadır. Örneğin Ö 3’ün "paralelkenarın karşılıklı kenarları eşittir, hepsi eşit olamaz" şeklindeki açıklamasının nedeni sorulduğunda, "kitapta belirtilen paralelkenar tanımına göre iki uzun iki klsa kenar sahip olması gerekir" şeklinde yanıt alınmıştır. Ayrıca günlük dilde kullanılan sözcükler ile matematik kavramlarının farklı anlamlar ifade etmesinden kaynaklanan öğrenci yanılgıları olduğu görülmüştür. Örneğin öğrencilerin geometrik bir şekil olan yamuk kavramını "düzgün olmayan şekil” ya da "bir yana doğru eğik olan şekil ya da nesneler" anlamında kullandıkları, dolayısıyla geometrik anlamını kavrayamadıkları, günlük dilde kullanılan “yamuk” sözcüğünü tanımladıkları belirlenmiştir.

\section{Tartışma, Sonuç ve Öneriler}

Elde edilen bulgulara göre öğrencilerin büyük çoğunluğunun geometrik kavramları tanımlama, sınıflama ve aralarındaki ilişkileri belirleme ile ilgili kavram yanılgıları ve bilgi eksiklikleri olduğu sonucuna varılmıştır. Öğrenciler bu konuları ilkokul 2. sınıftan itibaren öğren- 
Ege Eğitim Dergisi 2017 (18) 1: 83-104

Çokgenlerle İlgili Kavram Yanılgıları ve Olası Nedenler

meye başlamakta ve her yıl daha kapsamlı bir şekilde öğrenmektedirler. Özellikle dörtgenler ve üçgenleri oluşturan temel kavramlara (açı, kenar, köşegen vs.) ilişkin yanılgıların, öğrencilere bu konular öğretilirken yeteri kadar somutlaştırma yapılmadığı ve günlük hayatla ilişkili örnekler verilmediğinden; materyal kullanılmadan öğretim faaliyetlerinin gerçekleştirilmeye çalışılmasından ve ezbere dayalı bir öğretim yapılmasından kaynaklandığg düşünülmektedir. Çünkü öğrencilerin sorulara verdikleri yanıtlara bakıldığında, belli kurallara bağlı kaldıkları; benzer tanımlamalar yaptıkları ve özgün ifadeler kullanamadıkları görülmektedir. Bu durum öğrencilerin kavramları sadece soyut birer tanım ya da özellik olarak algıladıkları; gerçek yaşamdan nesnelerle ya da farklı şekillerle bu kavramların ilişkilendirilmediği şeklinde yorumlanabilir. Türnüklü ve Berkün (2013) tarafından yapılan çalışmada da öğrencilerin zihinlerindeki çokgen şemalarının sınırlı olmasından dolayı karşılaştıkları çokgen çeşitlerini yanlış sınıflandırdıkları, ve çokgenlerin öğretiminde prototip örnekler kullanılarak bir çokgene ait farklı şekil örnekleri verilmemesi sonucu öğrencilerin kavram yanılgılarına neden olduğu şeklinde bulgular elde edilmiştir. Ayrıca kullanılan ders kitaplarının teorik olarak yanlış olan bilgiler içermesi ve yeterli sayıda örnek sunmaması da kavram yanılgılarına neden olabilir. Zilkova (2014) tarafından yapılan araştırmada da kullanılan geometri kitaplarının bazı çokgenleri yanlış sınıflandırması sonucunda öğrencilerde kavram yanılgıları oluştuğu şeklinde sonuçlar elde edilmiştir. Van Hiele'in geometrik düşünme düzeylerine göre ortaokulda öğrenim gören öğrencilerin ikinci düzey olan informal çıkarım düzeyine ulaşmaları beklenmektedir (Altun, 2014; Olkun, Toluk Uçar, 2006). Ancak araştırmaya katılan öğrencilerin bu düzeyin özellikleri olan şekillerin özellikleri arasında ilişkiler kurma ve mantıksal sıralama yapma gibi davranışları gösteremedikleri belirlenmiştir. Hatta araştırmaya katılan öğrencilerin birçoğunun sıfır düzeyinin özelliklerinden bazılarına bile sahip olmadıkları belirlenmiştir. Çünkü öğrenciler şekillerin farklı görünüşleriyle karşılaştıklarında bu şekilleri tanımlayamamaktadırlar. Monaghan (2000) tarafindan yapılan araştırmada öğrencilerin bir düzeyden sonraki düzeye geçememelerinin nedeninin, öğretmen ve öğrencilerin aynı kavramı farklı düzeylerde sorgulamaları şeklinde ifade edilmiştir.

Araştırma bulgularına göre öğrencilerin aşırı genelleme yaparak yanılgılar oluşturdukları da belirlenmiştir. Öğrencilerin şekillerin özelliklerini anlamlandırma yerine aşırı genelleme yapmaları, her durumu bir kuralla ilişkilendirmeye çalışmalarından kaynaklandığı düşünülmektedir. Ayrıca kullanılan dilden kaynaklanan yanılgıların oluşmasında öğrencilerin ailelerinin, yetiştikleri çevrenin ve kültürün de etkisi olduğu savunulabilir. 
Bulgulardan elde edilen bir diğer sonuç ise öğrencilerin sadece kavramsal değil, işlemlerle ilgili de bazı sorunlar yaşadıkları şeklindedir. Özellikle çokgenlerin alan ve çevre hesaplamaları ile ilgili olan sorularda öğrencilerin kavramsal ilişkileri kuramadıkları gibi, problemi anlama ve işlem yapma becerilerinin de zayıf olduğu sonucuna varılmıştır. Baykul (2005) buna benzer bir durumu "kavramların oluşmaması, kavramlarla işlemler arasındaki bağın kurulmaması veya her iki durumun birlikte gerçekleşmesi durumunda öğrenciler işlemsel yanılgılara düşebilirler" şeklinde açıklamaktadır. Bu bağlamda öğrencilerin bir çokgene ait çevre uzunluğu ve alanı hesaplamak için gereken kavramlarla ilgili sahip olduğu yanılgıların, işlem yapma becerilerini de engellediği düşünülmektedir.

Araştırmadan elde edilen bulgulara göre öğrencilerin bir kavram yanılgisı oluşturmasında bazen tek bir etmen değil, birden fazla etmenin rol aldığ 1 görülmüştür. Örneğin öğrenci, öğretmenin bir ifadesini yanlış yorumlayabilmekte, daha sonra bu yoruma uyan herhangi bir olay ya da durumla karşılaştığında bunu önceki yanılgısına dayanak yapabilmektedir. Bu nedenle yeni bir kavramın ya da konunun öğretimine başlamadan önce öğrencilerin o konuyla ilgili olan ön bilgilerinde yanılgıların olup olmadığı tespit edilmeli, var olan kavram yanılgıları giderildikten sonra yeni kavramların öğretimine geçilmelidir.

Yedinci sınıf matematik öğretim programında çokgenler konusuyla ilgili kazanımların öğretimi için ortalama 18 ders saati ayrılmaktadır. Bir derste kazandırılması beklenen davranış sayısında önceki programa göre gelişme olması sevindiricidir. Ancak örnekleme alınan okullarda sınıfların kalabalık olduğu (en az otuz beş, en çok elli dört öğrenci) göz önünde bulundurulursa, öğrencilerin konularla ilgili bilgi eksikliği ve dolayısıyla kavram yanılgıları olması kaçınılmazdır. Çünkü bu tür sınıflarda öğretmenler konuları yetiştirebilmek amacıyla sunuş yoluyla öğretim yapmakta, bu da kavramların öğrenciler tarafından yapılandırılmasını engellemekte ve dolayısıyla kavram yanılgıları oluşabilmektedir. Oysa yapılandırmacı öğrenme ortamlarında öğrencilere yaşamda yer alan problemlere dayalı, etkileşime dayalı ve zengin ortamlar sunulması beklenmektedir. Bu nedenle öğrencilerin yaparak yaşayarak öğrenebilecekleri, öğrenme etkinliklerinin bol miktarda yapılabileceği öğrenme ortamları oluşturulmalı ve öğretmenlerin özellikle soyut kavramların öğretiminde mümkün olduğunca bilgisayar destekli öğretimden ve teknolojik olanaklardan faydalanmaları sağlanmalıdır. Bu bağlamda matematik dersinde içerik yoğun bir öğretim yerine uygulama ve etkinlik ağırlıklı bir öğretim benimsenmesinin, kavramların doğru öğrenilmesi açısından daha faydalı olacağına inanılmaktadir. 


\section{Kaynakça}

Aksu, M. (1991). Problem çözme süreci: Matematik öğretimi, (Ed. B. Özer), Eskişehir, Anadolu Üniversitesi, Yayın No: 401, Açık Öğretim Fakültesi Yayın No: 160, 52 - 69.

Altun, M. (2014). Liselerde matematik öğretimi. Alfa Aktüel Yayınları.

Ayas, A., Karamustafaoğlu, S., Cerrah, L. ve Karamustafaoğlu, O. (2001, Haziran). Fen bilimlerinde öğrencilerdeki kavram anlama seviyelerini ve yanılgılarını belirleme yöntemleri üzerine bir inceleme. X. Ulusal Eğitim Bilimleri Kongresi, Abant İzzet Baysal Üniversitesi, Cilt II, 839-852.

Baykul, Y. (2005). Illköğretimde matematik öğretimi (1-5.Sinıflar). (8. Baskı). Ankara: Pegem Yayınları.

Byrd, C.E., McNeil, N. M., Chesney, D. L. ve Matthews, P.G. (2015). A specific misconception of the equal sign acts as a barrier to children's learning of early algebra. Learning and Individual Differences 38(2015), 61-67.

Comins, N.F. (1998). Identifying and addressing astronomy misconceptions in the classroom. İçinde L. Gouguenheim, D. McNally, ve J.R. Percy (Ed.), New trends in astronomy teaching. (s.118-123). Cambridge University Press. ISBN 0521623731.

Coştu, B. (2002). Ortaöğretimin farklı seviyelerindeki öğrencilerin buharlaşma yoğunlaşma ve kaynama kavramlarını anlama düzeylerine ilişkin bir çalışma. (Yayımlanmamış Yüksek Lisans Tezi). Karadeniz Teknik Üniversitesi, Fen Bilimleri Enstitüsü, Trabzon.

Creswell, J.W. (2007). Educational research, educational research: Planning conducting and evaluating quantitative and qualitative research. (3. Bask1). Pearson: Merrill Prentice Hall.

Çelik, L. (1996). Piaget"nin zihinsel gelişim kuramına göre ilköğretim matematik dersi programının değerlendirilmesi. (Yayımlanmamış Yüksek Lisans Tezi). Afyon Kocatepe Üniversitesi, Sosyal Bilimler Enstitüsü, Afyon.

Dane, A. (2008). İlköğretim matematik 3. sınıf öğrencilerinin tanım, aksiyom ve teorem kavramlarını anlama düzeyleri. Kastamonu Eğitim Dergisi, 16(2), 495-506.

Duman, A. (2006). İlköğretim öğrencilerinin matematik başarısını etkileyen faktörlerin öğrenciler ve öğretmenler açısından değerlendirilmesi (Eskişehir İli Örneği). (Yayımlanmamış Yüksek Lisans Tezi), Eskişehir Osmangazi Üniversitesi Sosyal Bilimler Enstitüsü, Eskişehir. 
Elliott, S.N., Kratochwill, T.R., Littlefield Cook, J. ve Travers, J. F. (2000). Educational psychology: Effective teaching, effective learning. (3. Bask1). USA: McGraw-Hill Companies.

Ercan, B. (2010). İlkögrretim yedinci sınıf öğrencilerinin tam sayı kavramı ile ilgili bilgilerinin değerlendirilmesi. (Yayımlanmamış yüksek lisans tezi). Çukurova Üniversitesi, Sosyal Bilimler Enstitüsü, Adana.

Erden, M. ve Akman, Y. (2004). Gelişim ve öğrenme. Ankara: Arkadaş Yayınevi.

Fraenkel, J.R., Wallen, N.E. ve Hyun, H.H. (2012). How to design and evaluate research in education. (8. Bask1). New York: McGraw-Hill Companies.

Karataş, F.Ö. (2002). Lise 2 kimyasal denge konusunun ögretiminde bilgisayar paket programları ile klasik yöntemlerin etkililiğinin karşılaştırılması. (Yayımlanmamış Yüksek Lisans Tezi). Karadeniz Teknik Üniversitesi, Fen Bilimleri Enstitüsü, Trabzon.

Koklu, O. ve Topcu, A. (2012). Effect of Cabri-assisted instruction on secondary school students' misconceptions about graphs of quadratic functions. International Journal of Mathematical Education in Science and Technology, 43(8), 999-1011.

MEB, (2013). Ortaokul matematik dersi (5,6,7 ve 8. sinıflar) öğretim programı. Ankara.

Meşeci, B., Tekin, S. ve Karamustafaoğlu, S. (2013). Maddenin tanecikli yapısıyla ilgili kavram yanılgılarının tespiti. Dicle Üniversitesi Sosyal Bilimler Enstitüsü Dergisi, 5(9), 8-40.

Monaghan, F. (2000). What difference does it make? Children's views of the differences between some quadrilaterals. Educational Studies in Mathematics, 42(2),179-196.

Olkun, S. ve Toluk Uçar, Z. (2006). İlköğretimde matematik öğretimine çağdaş yaklaşımlar. Ankara: Ekinoks Yay.

Ojose, B. (2015). Students' misconceptions in mathematics: Analysis of remedies and what research says. Ohio Journal of School Mathematics,72, 30-34.

Osborne, R. J. ve Gilbert, J. (1980). A method for the investigation of concept understanding in science. European Journal of Science Education, 2(3), 311-321.

Özdeş, H. ve Elitok Kesici, A. (2015). 9. sınıf öğrencilerinin doğal sayılar konusundaki hata ve kavram yanılgıları. Kastamonu Eğitim Dergisi, 23(3), 1277-1292.

Özmantar, M.F., Bingölbali, E. ve Akkoç, H. (2013). Matematiksel kavram yanılgıları ve çözüm önerileri (3. Baskı). Ankara: Pegem Akademi Yayıncılık. 
Resnick, L. B., Nesher, P., Leonard, F., Magone, M., Omanson, S., \& Peled, I. (1989). Conceptual bases of arithmetic errors: The case of decimal fractions. Journal for Research in Mathematics Education, 20(1), 8-27.

Senemoğlu, N. (2013). Gelişim, ögrenme ve ögretim, (23. Bask1). Ankara: Yargı Yayınevi.

Sivacı, S.Y. (2003). Sinıf Öğretmenliği son sınıf ögrencilerinin matematik alan ve meslek bilgisi yeterlikleri ile derse yönelik tutumları. (Yayımlanmamış Doktora Tezi). Hacettepe Üniversitesi, Sosyal Bilimler Enstitüsü, Ankara.

Stacey, K., Helme, S., Steinle, V., Baturo, A., Irwin, K. ve Bana, J. (2001). Preservice teachers' knowledge of difficulties in decimal numeration. Journal of Mathematics Teacher Education, 4(3), 205-225.

Stafylidou, S. ve Vosniadou, S. (2004). The development of students' understanding of the numerical value of fractions. Learning and Instruction, 14(5), 503-518.

Stefanich, G.P. ve Rokusek, T. (1992). An analysis of computational errors in the use of division algorithms by fourth-grade students. School Science and Mathematics, 92(4), 201205.

Ülgen, G. (2001). Kavram geliştirme. (3. Baskı), Ankara: Pegem A Yayıncılık.

Temizkan, M. (2011). Türkçe öğretmeni adaylarının temel dil becerilerinden okuma ile ilgili kavramları öğrenme düzeyleri ve kavram yanılgıları. Dicle Üniversitesi Ziya Gökalp Ĕ̈itim Fakültesi Dergisi, 17 (2011) 29-47.

Türkdoğan, A., Güler, M., Bülbül, B. Ö. ve Danişman, Ş. (2015). Studies about misconceptions in mathematics education in Turkey: A thematic review Mersin University Journal of the Faculty of Education, 11(2), 215-236.

Türnüklü, E. ve Berkün, M. (2013). İlköğretim 5 ve 7. sınıf öğrencilerinin çokgenleri sınıflandırma stratejileri. Kastamonu Ĕ̈itim Dergisi, 21(1), 337-356.

Yıldırım, A. ve Şimşek, H. (2011). Nitel araştırma yöntemleri. (8. Baskı). Ankara: Seçkin Yayınevi.

Yılmaz, K. ve Çolak, R. (2011). Kavramlara genel bir bakış: Kavramların ve kavram haritalarının pedagojik açıdan incelenmesi. Atatürk Üniversitesi Sosyal Bilimler Enstitüsü Dergisi, 15 (1), 185-204. 
Ege Eğitim Dergisi 2017 (18) 1: 83-104

Çokgenlerle İlgili Kavram Yanılgıları ve Olası Nedenler

Zembat, İ.Ö. (2013). Kavram yanılgısı nedir? İçinde Özmantar, M.F., Bingölbali, E., ve Akkoç, H. (Ed.) Matematiksel kavram yanılgıları ve çözüm önerileri, (3. Bask1). (s. 1-8). Pegem Akademi: Ankara.

Zilkova, K. (2014). Parallelogram conceptions and misconceptions of students who study to become teachers in pre-primary and primary education. Indian Journal of Applied Research, 4(7), 128-130. 


\section{Extended Summary}

Mathematics curricula have been revised in order to help students learn mathematics better. New mathematics curriculum bases upon theory of conceptual learning and advocates that students should learn the relationship between the cause and effect of concepts, instead of just memorizing meaningless and non-relational operations or formulas (Erden \& Akman, 2004). Conceptual learning places more importance on constructing conceptual bases of mathematical knowledge in order to relate conceptual and operational knowledge and abilities (MoNE, 2013).

When learning and teaching concepts, there could be some obstacles called "misconceptions” (Byrd, McNeil, Chesney, \& Matthews, 2015). Misconceptions can be defined as "faulty thoughts or interpretations of learners due to lack of knowledge” (Ojose, 2015), or “concepts that conflict with experts’ opinion” (Zembat, 2013). Misconceptions are encountered especially in disciplines like mathematics in which many abstract concepts are learned consecutively and new knowledge is constructed on the previous (Türkdoğan, Güler, Bülbül, \& Danişman, 2015). In such disciplines, it is very likely that students will have misconceptions in their new-learned concepts if their older concepts are learned as misconceptions (Stafylidou, \& Vosniadou, 2004). Therefore, it is very important that educators give importance diagnosing students' misconceptions on mathematical concepts and eliminate them before teaching new concepts (Osborne \& Gilbert, 1980; Resnick et. al., 1989).

In this study sequential explanatory mixed method design was conducted in order to determine elementary students' misconceptions and their reasons on polygons. In this type of design the researcher first apply quantitative method and then collect qualitative data in order to refine quantitative data (Fraenkel, Wallen ve Hyun, 2012) and quantitative and qualitative data are analyzed seperately (Creswell, 2007).

The target population of the study consisted of all $7^{\text {th }}$ grade elementary students who were registered in public schools located in the central towns of İzmir in 2013-2014 academic year. The sample of the study was determined through systematic sampling method among those schools. 424 seventh grade students participated in the study. Of the participants, $56 \%$ was female and $44 \%$ was male. The data of the study were collected through a two-tier Test for Polygonal Misconceptions (TFPM) and an interview form which were developed by the researcher. During the construction of the test, 47-item trial form was prepared in order to measure objectives of the 7th grade mathematics program. After items were checked by experts from curriculum and instruction, measurement and evaluation, mathematics education, 
Ege Eğitim Dergisi 2017 (18) 1: 83-104

Çokgenlerle İlgili Kavram Yanılgıları ve Olası Nedenler

Turkish education departments and three elementary mathematics teachers, trial form was applied to 343 students. Then the difficulty and discrimination index of each item were calculated. For each objective, one item that has the highest discrimination index and medium-level difficulty was selected and 15-item test was constructed. According to statistical calculations KR-20 reliability coefficient of the test was found .74, average difficulty was found .37; standard deviation was found 3.26; and mean was found 5.52. After last version of the test was prepared, explanation parts were added for each item on the test.

Another data collection tool used in the study was interview form which was used in order to determine the reasons of misconceptions. There were 13 open-ended questions in the form asking characteristics of geometrical shapes, relations between them and what students encounter during learning teaching process. Before conducting the form, it was checked by three experts and re-organized.The answers of students for the first tier of items were coded as "Correct”, "Wrong” and "No answer" and then these answers were analyzed with percentage and frequency. The second tier of the items were analyzed by using categories "Full Understanding”, "Partial Understanding”, "Lack of Knowledge”, “Misconception” and "No Answer”. The data obtained from interviews were first transcribed and then analyzed through content analysis. The interviews were investigated under four themes that cause misconceptions namely students, teacher, materials used during teaching and language attributes.

According to the findings of the study, it was concluded that students had various misconceptions concerning such issues as the characteristics, classification and definition of polygonal concepts and determining relations among these concepts. Some of the misconceptions are "the area of a parallelogram is measured by multiplication of two parallel sides", "the hypotenuse of a triangle can be shorter than other two sides", "the diagonals of a rhombus do not have to intersect each other with right angle". The findings obtained from TFPM showed that although one gives wrong answer for the first tier of an item, this does not always mean that he/she has misconceptions on that issue. The findings obtained from interviews revealed that factors derived from students' own attributes or knowledge, incompetence of teachers in the teaching process, materials and tools and several linguistic properties underlie these misconceptions. The reasons derived from students' own attributes are lack of knowledge on a certain issue/topic, overgeneralization, ignoring essential and sufficient points that should be in a definition, having difficulties when using mathematical language. In addition, wrong examples, improper analogies and teaching strategies that are given by teachers may also cause misconceptions. The answers of students during interview revealed that when they are asked 
for how to construct a certain polygon, they constructed same type and prototypical polygons. This may show that they are taught by teachers with prototype examples in class. Moreover, when students are asked for their reasons to the questions, they give reference textbooks and explanations in those mathematics books. This shows that textbooks may also be a cause for misconceptions. Lastly, the findings proved that the attributes of language may cause misconceptions. For example, since the Turkish meaning of "trapezoid" is the same with "irregular", students get confused if they are asked the attributes of that polygon, and this may cause misconception.

Depending on these findings, teachers should facilitate learning environments in which students participate actively in learning activities. In addition, students should learn with real life problems and interact with their peers. Before teaching teachers should detect students' previous misconceptions and help to eliminate them. 